\title{
INVESTIGATING THE RELATIONSHIP BETWE- EN THE USE OF DOMESTIC RADIO AND THE LEVEL OF SOCIAL TRUST
}

Morteza Farajian ${ }^{1}$

\begin{abstract}
This study studies
use of radio program signifithe relationship between radio cantly affects interpersonal trust. usage and social trust. We have Examining the relationship beconsidered trust in three types: tween the use of different types interpersonal trust, general and of radio programs with the interinstitutional trust. The research mediate variables of the research method used in this research is shows that there is a significant the survey method that the reserelationship between the use of arch data was collected using a radio and the intermediate vaquestionnaire in the field. Also, 383 samples were selected and riables of generalism and the feeling of security. The results operated by systematic cluster showed that there is a significant sampling. The results show that relationship between research there is a significant relationship mediating variables and the level between radio usage and general of social trust in its types of trust. trust. But there is no significant All research mediating variables relationship between radio usahave a significant relationship ge and institutional trust. The with institutional trust. Finally, it results showed that between the can be stated that the use of ra-
\end{abstract}

1 Department of Sociology, Parsabad Moghan Branch, Islamic Azad University, Parsabad Moghan, iran

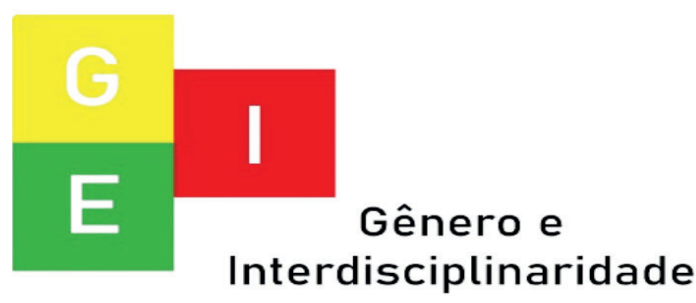


Vol. 02 - n 06 - ano 2021

Editora Acadêmica Periodicojs

dio affects the level of social trust by directly affecting social trust and also by indirectly influencing through research interface variables.

Keywords: social trust, interpersonal trust, general trust, institutional trust, radio.

\section{Introduction}

Trust is one of the most important concepts in the field of sociology of order. This importance is rooted in the first place in the position of trust in social action. Nicholas Luhmann, a theorist in the field of trust, has a functional view of trust from the perspective of controlling and predicting social action, especially in modern society, which is associated with complexity, risk or risk. In this situation, trust plays an important role in deter- mining and maintaining social order. (Misztal 1996: 73) Zetompka, Coleman, and Giddens also attribute this function to social trust. It is called social.

The present study with a social approach has considered trust in three types: interpersonal, general and institutional. Interpersonal trust is considered at the levels of a face-to-face relationship. In this type of trust is addressed to friends, acquaintances and family members. Public trust goes beyond a relationship and on a broader level. The goal is not the trust of a certain person, but in general, for example, trust in women versus men or trust in different races and nationalities. Ultimate trust refers to formal or informal institutions and organizations, and to impersonal structures in general.

In the present study, social trust has been considered as

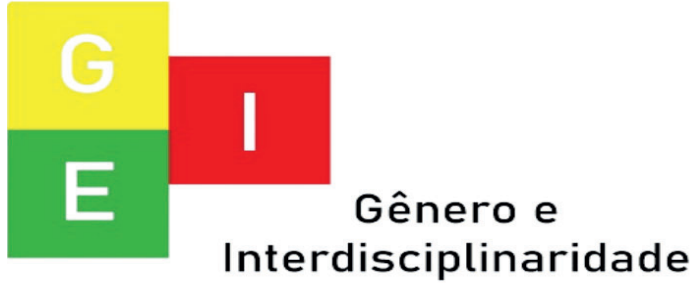


ISSN: 2675-7451

Vol. 02 - n 06 - ano 2021

Editora Acadêmica Periodicojs

a dependent variable in relation to domestic radio media as an independent variable. It is true that the use of radio as a medium has decreased today, but it seems that the majority of people in the study community still use this medium. So the questions that can be asked in this case are whether the radio media increase or weaken the social trust of people in the city? What effect does the use of media, which means the use of different radio programs, have on the level of social trust of individuals? To what extent does the social status of individuals play a role in influencing people from radio media and its impact on social trust? The present study tries to give a proper answer to the questions raised and finally to answer the basic question of the research that:

Is there a relationship between the use of radio and the level of social trust in the city?

\section{Theoretical foundations of re-} search

"Trust in a Social Theory" is the title of a book in which Ztompka discusses trust. Zetompka's approach to trust in this book, as its title implies, is a social one. Dalhi and Newton also classify Ztompka as social theorists in their work. However, in explaining the basics of trust, Zetompka also pays attention to individual and psychological factors.

Ztompka defines trust as a type of betting that is based on the actions of others in the future (Sztompka.1999: 25). Has analyzed it. One of the factors influencing trust in Zetompka theory is the degree of reliability, which is closely related to the information element. Zetompka has defined

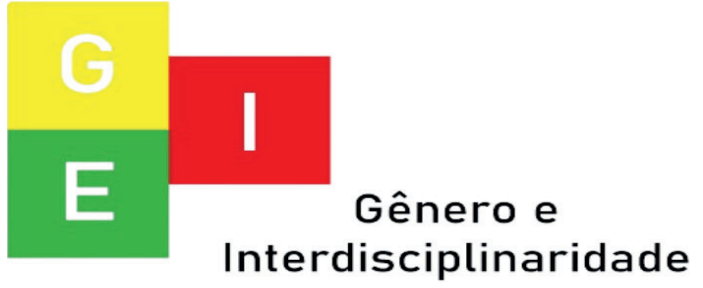


Vol. 02 - n 06 - ano 2021

Editora Acadêmica Periodicojs

various sources for this information, one of the most important of which is information technology. An important source of trust in Ztompka's theory is the collective rules and norms of trust that are institutionalized and acted upon through socialization within individuals.

Robert Putnam published two books, The Application of Democracy and Italian Civil Traditions (1993), a research paper on civil society in parts of Italy, and Solo Bowling (1995). The research product on the decline of civil society in the United States has become a well-known figure in social capital issues. Putnam's discussion of social trust has also taken place in the context of social capital. The reason for Putnam's choice among social capital theorists goes back to Putnam's clear discussion of the impact of mass media on so- cial capital in general and social trust in particular. Social trust and its relationship to the mass media have come to Putnam's mind. In defining social capital, Putnam writes, "Social capital is concerned with the relationships between individuals on social networks, the norms of exchange, and the trust between them" (Putnam 2000: 19).

The mass media have a prominent place in the Putnam debate as factors affecting social capital in general and social trust in particular (Norriss 2002: 9). In the meantime, he has a special role for television. Putnam argues, based on a wealth of evidence, that television has played a significant role in the decline of the American social capital from 58 percent in 1960 to 37 percent in 1993. Much of this decline has been in social trust (Putnam, 1998: 74).

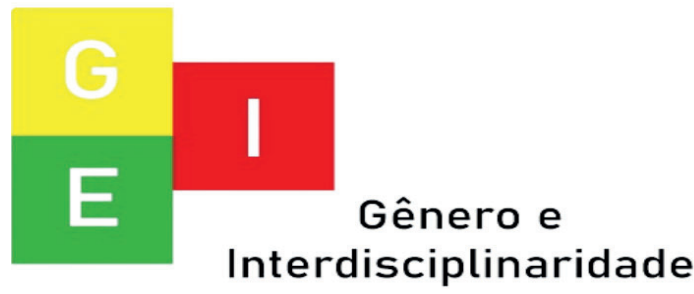


ISSN: $2675-7451$

Vol. 02 - n 06 - ano 2021

Editora Acadêmica Periodicojs

Putnam's claim against television on the socialization

television is based on two main process of individuals (Uslaner, directions. The first is related 1998).

to the effects of television on the personality of individuals and especially the role of this media in the process of socialization of individuals and in another direction it is related to the amount of time people spend on television, time factor or level of civic participation. It is close. At first glance, Putnam sees television as a particular technological breakthrough. In this view, Putnam links his discussion to the history of television in the United States and its demographic changes. Born in 1940 is greater because they were not influenced by television as children. Putnam argues that increased television viewing is effective in reducing social trust and membership in voluntary organizations, and that this is through the influence of

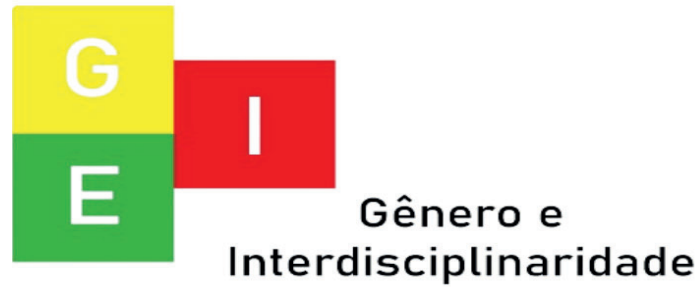

(Putnam 1998: 74).

Giddens's work on trust explains its conditions and characteristics in both modern and traditional societies. In addition, Giddens defines the general characteristics of trust that are the product of a psychological approach, here only a brief reference to the general dimension of Giddens's discussion of trust. Gid- 
Vol. 02 - n 06 - ano 2021

Editora Acadêmica Periodicojs

dens argues that there is always a deliberate self-awareness and faith behind the continuation of the order of daily life, which is accompanied by anxiety and fear of fragility. Belief in the continuity and continuity of one's identity and the social and material environment around individuals, something that refers to a sense of existential security (Giddens, 2003: 60).

In his discussions, Giddens has made two distinct classifications centered on modernity. The first is the division of dimensions of modernity and the second is the classification of the types of forces of modernity. Giddens has defined four dimensions for modernity. These four dimensions are:

1-Capitalism: means the accumulation of capital in the field of labor and competitive market production. 2- Indus- trialism: the use of inanimate resources, material forces in the production of goods always with the central role of machinery in the production process. Monitoring the means of controlling violence and industrialization of war 4- Protection: including monitoring information and social care (quoted and summarized, Giddens, 1999: 76-67).

As can be seen, Giddens places information in the fourth dimension of modernity, which defines it as taking care of the activities of a country's citizens in the realm of politics. Explaining this dimension, he says, "The emergence of modernity is first and foremost with the modern economic order, that is, the capitalist economic order, but modern society is also concerned with the formation of a particular type of government or, in general, specific types of orga-

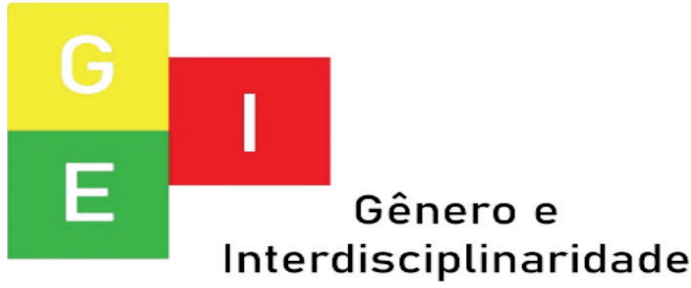


ISSN: $2675-7451$

Vol. 02 - n 06 - ano 2021

Editora Acadêmica Periodicojs

nizations involved." That is why

I use the idea of "surveillance"

borrowed by Foucault as a way

in which intelligence systems are

formed to create new systems of

organizational power. The mo-

dern state is a genuine example

of this process "(Pearson, 2001:

168). According to Giddens'

theory, McLuhan and Ainis defi-

ne the role of the mass media in

social development, especially in

relation to modernity. Contrary

to popular belief, the ability of

any medium to change the rela-

tionship between time and spa-

ce is not primarily related to the

content or "message" that results,

but to the shape and reproducibi-

lity of the medium in question.

Ainis, for example, points out that the emergence of papyrus as a medium for recording writings greatly expanded the scope and authority of administrative systems, as papyrus-made paper was much easier to store, store, and reproduce. It was one of the materials that were previously used for this purpose (Ibid: 45).

According to Giddens, trust in specialized social institutions is rooted in a lack of awareness, knowledge and expertise. Giddens plays a decisive role for the mass media in modern society. The role that is closely related to the forces of modernity. Connecting and accessing abstract systems plays an important role in strengthening and undermining social trust.

\section{Theoretical (analytical) fra- mework of the research}

As mentioned in the theoretical discussion of the research, social trust as a social matter is influenced by various factors. Based on the theories discussed, effective factors such as sense

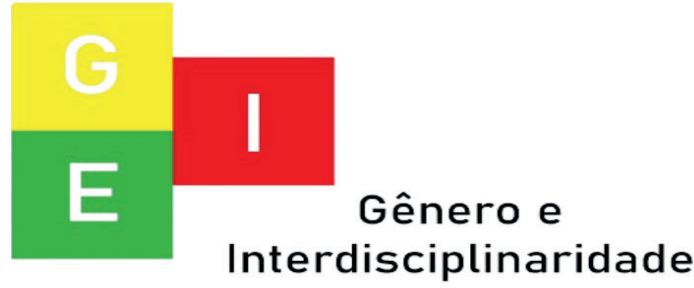


Vol. 02 - n 06 - ano 2021

Editora Acadêmica Periodicojs

of security, universalism, social participation, fundamental trust, socialization and the use of mass media can be named.In the present study, among the various factors affecting social trust, we will examine the relationship between the use of radio mass media and the level of social trust.

According to various theories related to social trust, there is a relationship between the use of mass media and the level of social trust of individuals. However, the direction of this relationship in different theories has been reported in a different way. The difference between the relationship between media and social trust in the theories has practically obscured the relationship between media and social trust. Giddens, for example, considers social trust to be based on a lack of information, while Coleman and Zetompka, two theorists of trust, emphasize

the key role of information in the trust process.

Zetompka introduces information as one of the foundations of trust, and this is exactly the opposite of Giddens's claim. Coleman and Zetompkai have cited mass media as the main sources of this information, and from this perspective, they have considered the relationship between mass media and social trust. Accordingly, Robert Pontam defines for mass media, especially television, an effective role in the decline of social capital in general and social trust in particular. This role is played in the form of creating an "ugly world" in the minds of the audience, thus the function of monitoring the environment becomes a dysfunction. However, the information we receive does not always lead to such an image, it helps us to assess the

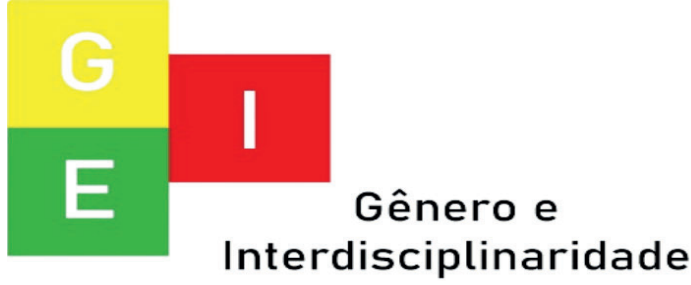


ISSN: 2675-7451

Vol. 02 - n 06 - ano 2021

Editora Acadêmica Periodicojs

situation, make decisions and satisfy curiosity, which is one of the main causes of mental mobility.

Vishah examines the relationship between media and social trust in shaping the patterns that people emulate in their lives, allowing them to relate to others (vi shah 1998: 475). In this regard, Dalgran uses the phenomenological sociological theory of Schutz, Berger, and Lockman, in the sense that the media provide patterns of action in Schutz's interpretation and symbolic worlds in Berger and Lockman's interpretation for actors in everyday life. In this way, the media, through the process of socialization and their role in creating symbolic unity, make it possible for individuals to relate to each other according to general rules. The result is universalism, followed by an increase in social trust.
In this way, the mass media play an effective role in reducing social isolation and creating a sense of common ground and empathy with society among individuals. The result is the formation of a sense of belonging, so that the identity of a society is placed at the top of other identities, as a result of which public commitment is strengthened, and this in turn increases social trust in society. It should be noted that the title of mass media is a general term that includes various mass media that have been considered in this research of radio media.

\section{Research Hypotheses:}

- There is a relationship between the use of domestic radio and various types of social trust.

- There is a relationship

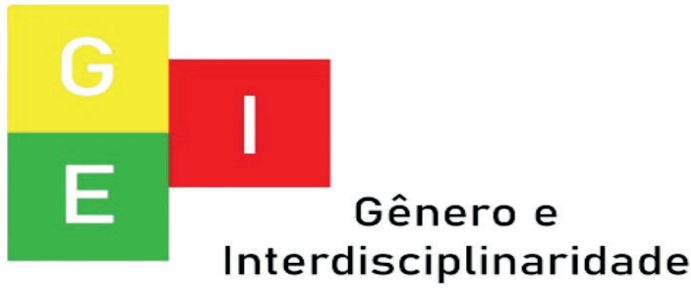


Vol. 02 - n 06 - ano 2021

Editora Acadêmica Periodicojs

between the use of various types of internal radio media messages and types of social trust.

The rate of radio use affects the social trust of the audience by influencing factors such as evaluation of the social environment, evaluation of officials, generalization, sense of security, and social commitment.

\section{Methodology}

In this research, we use the correlational survey method for several reasons. The research design of this survey is selected from a cross-sectional type. In this type of research, in order to describe and measure the degree of correlations or relationships of the variables of the society from which the sample is selected, information is collected from the sample at a certain time. The method of data collection in this stu- dy is a questionnaire that has the ability to collect a large amount of information accurately.

The subject of this study is to investigate the relationship between the use of mass television television and the level of social trust in Parsabad city and that the issue of social trust is such that it seems that people should be at a certain age in terms and conditions of trust. In this study, people in this age range have more social interactions than their younger ages, and compared to other age groups in their social interactions, goals and benefits. They follow a more specific one.

In this study, because the statistical population constitutes a large volume of the population in the city, the multi-stage cluster sampling method will be used.

In this study, determi-

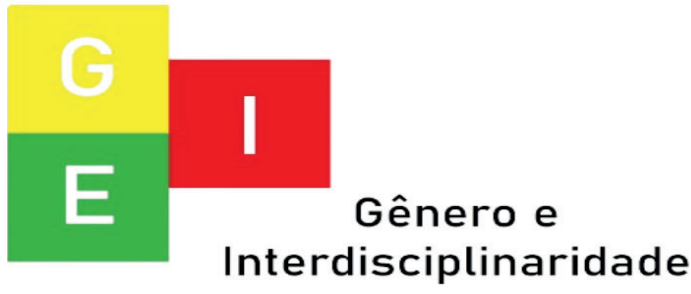


ISSN: $2675-7451$

Vol. 02 - n 06 - ano 2021

Editora Acadêmica Periodicojs

ning the sample size, assuming the level table below the standard that the sample distribution is normal curve, will be 1.96. The normal, an acceptable $95 \%$ confi- next step is to find a formula for dence interval is selected because estimating $\mathrm{n}$ samples, which is this reliability is common in the calculated approximately based social sciences. Thus, the requi- on the following formula, which red standard error number ( $\mathrm{t}$ ) to is a random sampling formula. achieve this coefficient, based on

$$
\mathrm{n}=\frac{N t^{2} s^{2}}{N d^{2}+t^{2} s^{2}}
$$

Statistical population people are randomly selected means $\mathrm{N}$ equal to 120,000 people from among the citizens.

- A reliability of $95 \%$ is assumed

\section{Findings}

\section{The rate of use of radio}

in the statistical sample is assumed to be a maximum of $(0 / 05)^{2}$

The confidence interval of generalization of the results to the statistical population is considered to be 0.1 , which results in $\mathrm{d}=0.05$.

The sample calculated according to the formula is 383
With the increasing expansion of television, radio has lost its fans, but it is still one of the most important mass media. Table (1) shows the frequency distribution and percentages of radio usage around the clock. As shown in the table. $61.1 \%$ of the respondents stated that they do

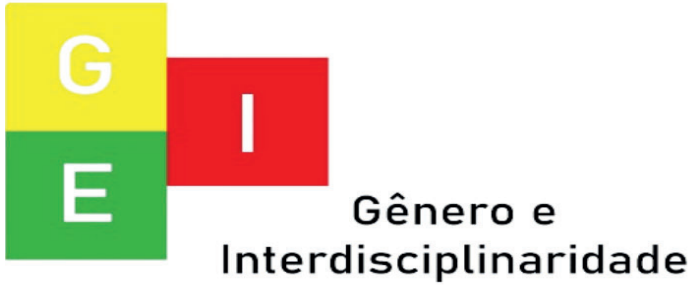


ISSN: 2675-7451

Vol. 02 - n 06 - ano 2021

Editora Acadêmica Periodicojs not use the radio at all during the stated that they use the radio for day and $25.6 \%$ of the respondents about 1 hour a day.

Table (1) Distribution of the frequency of listen to the radioper day by hour

\begin{tabular}{lcc}
\hline radio & Frequency & Percent \\
\hline Not at all & 234 & $61 / 1$ \\
About 1 hour & 98 & $25 / 6$ \\
About 1 to 3 hours & 36 & $9 / 4$ \\
About 3 to 6 hours & 6 & $1 / 6$ \\
More than 6 hours & 9 & $2 / 3$ \\
\hline Total & 383 & $100 /$
\end{tabular}

\section{Testing hypotheses}

Hypothesis 1: There is a relationship between the use of each radio with different types of social trust.

To test the first hypothesis, radio mass media as an inde- pendent variable and social trust variable is also tested at three levels (interpersonal, general and institutional trust). Becomes ble (2) Results of the correlation test between the radio

types of social trust

\begin{tabular}{lc} 
interpersonal trust & Kendall's tau- $\mathrm{b}=0 / 83$ \\
& Gamma $=0 / 162$ \\
& Sig $=0 / 079$ \\
General trust & Kendall's tau- $\mathrm{b}=0 / 226$ \\
& Gamma $=0 / 416$ \\
& $\mathrm{Sig}=0 / 000$ \\
Institutional trust & Kendall's tau- $\mathrm{b}=0 / 075$ \\
& Gamma $=0 / 102$ \\
& $\mathrm{Sig}=0 / 230$ \\
\hline
\end{tabular}

There is no significant relationship between radio usa0.079). Kendall's tau-b gamma

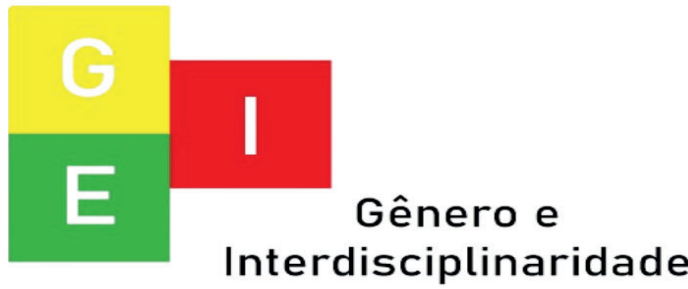


ISSN: 2675-7451

Vol. 02 - n 06 - ano 2021

Editora Acadêmica Periodicojs

and tau coefficients (Gamma $=$ 0.083) show that although there is a positive correlation between these two variables, this correlation is not significant. Between radio usage and trust In general, there is a significant relationship $(\operatorname{sig}=0.000)$. Gamma and tau-b coefficients of Kendall (Kendall's tau-b $=0.226,0.416($ Gamma $=$ indicates a relatively good relationship between these two variables in the positive direction of existence). This means that the higher the use of radio, the higher the level of public trust.There is no significant relationship between the use of radio and institutional trust $(\mathrm{sig}=0.230)$. Kendall's tau-b, $0.162($ Gamma $=$ show that although there is a positive correlation between these two variables, this correlation is not significant.

Hypothesis 2: There is a relationship between the use of different types of radio messages and different types of social trust.

To test the second hypothesis, ie the relationship between the use of different types of radio messages with different types of social trust, due to the rank of the level of measurement of variables, the test of gamma correlation coefficients and Kendall's t-test are used. In this way, the types of messages of each media are presented and explained in separate tables.

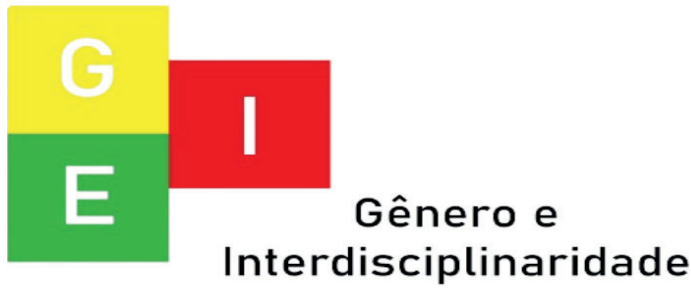


ISSN: 2675-7451

Vol. 02 - n 06 - ano 2021

Editora Acadêmica Periodicojs

Table (3) Results of the correlation test between the use of different types of radio programs with different types of social trust

\begin{tabular}{|c|c|c|c|}
\hline ypes of trusted & News programs & $\begin{array}{l}\text { Application rate } \\
\text { Entertainment programs }\end{array}$ & Educational programs \\
\hline Interpersonal trust & $\begin{array}{l}\text { Kendall's tau-b }=0 / 106 \\
\text { Gamma }=0 / 245 \\
\text { Sig }=0 / 017\end{array}$ & $\begin{array}{l}\text { Kendall's tau- } \mathrm{b}=0 / 087 \\
\text { Gamma }=0 / 189 \\
\mathrm{Sig}=0 / 063\end{array}$ & $\begin{array}{l}\text { Kendall's tau-b }=-0 / 105 \\
\text { Gamma }=-0 / 245 \\
\text { Sig }=0 / 024\end{array}$ \\
\hline General trust & $\begin{array}{l}\text { Kendall's tau-b }=0 / 189 \\
\text { Gamma }=0 / 392 \\
\text { Sig }=0 / 000\end{array}$ & $\begin{array}{l}\text { Kendall's tau- } b=0 / 176 \\
\text { Gamma }=0 / 359 \\
\mathrm{Sig}=0 / 000\end{array}$ & $\begin{array}{l}\text { Kendall's tau-b }=0 / 183 \\
\text { Gamma }=0 / 395 \\
\text { Sig }=0 / 000\end{array}$ \\
\hline Institutional trust & $\begin{array}{l}\text { Kendall's tau-b }=0 / 044 \\
\text { Gamma }=0 / 090 \\
\mathrm{Sig}=568\end{array}$ & $\begin{array}{l}\text { Kendall's tau-b }=0 / 057 \\
\text { Gamma }=0 / 113 \\
\quad \text { sig }=0 / 243\end{array}$ & $\begin{array}{c}\text { Kendall's tau-b }=-0 / 024 \\
\text { Gamma }=0 / 053 \\
\text { sig }=0 / 374\end{array}$ \\
\hline
\end{tabular}

Table (3) shows the relationship between the use of radio programs and the types of social trust. As the table shows, the use of radio news programs affects interpersonal trust, so there is a significant relationship between the use of radio news programs and interpersonal trust (sig = 0.017). Kendall's tau-b gamma and tau coefficients (Gamma $=$ 0.106) indicate that there is a significant correlation between radio news use and interpersonal trust. Has a significant effect on public trust (sig $=0.000)$ Kendall's tau-b gamma and tau coefficients (Kendall $=$ tau $-\mathrm{b}=0.189)($ Gamma $=$ show that the effect of radio news programs on trust) General social is more than interpersonal social trust, but there is no significant relationship between the use of radio news programs and institutional trust.

The use of entertainment programs among the types of social trust only significantly affects general trust $(\mathrm{sig}=0.000)$. Kendall's tau-b gamma and tau coefficients $(0.176=$ Kendall's tau-b, Gamma $=0.359)$ indicate

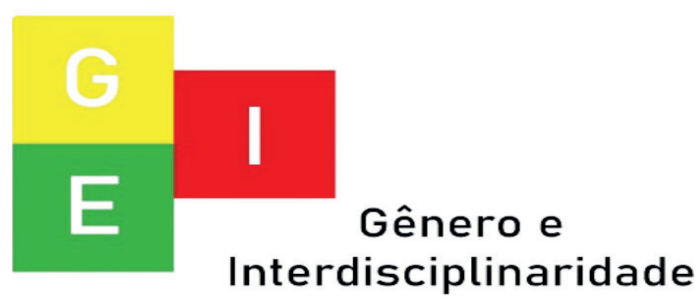


ISSN: 2675-7451

Vol. 02 - n 06 - ano 2021

Editora Acadêmica Periodicojs

that there is a significant correlation between these two variables, but between the use of radio entertainment programs and the trust between There is no significant relationship between individual and institutional trust.

As can be seen in the table, there is a significant relationship between the use of radio training programs and interpersonal trust $(\operatorname{sig}=0.024)$. Kendall's tau-b gamma and tau coefficients (- 0.05 - Kendall's tau-b, $0.245(\mathrm{Gamma}=-)$ indicate that the correlation direction is negative, meaning that the lower the use of radio training programs, the There is also a significant relationship between the use of radio training programs and the level of general trust $(\operatorname{sig}=0.000)$. Kendall's tau-b gamma and tau coefficients (Kendall's tau-b = 0.183, $0.395 \quad$ Gamma $=$ shows that the correlation between the two variables is at a considerable level and the intensity of the correlation between them is more than the intensity of the correlation with interpersonal trust, but no significant relationship was observed between the use of educational programs and institutional trust.

\section{The third hypothesis}

The use of radio affects the social trust of the audience by influencing factors such as evaluation of the social environment, evaluation of officials, universalism, sense of security, and social commitment.

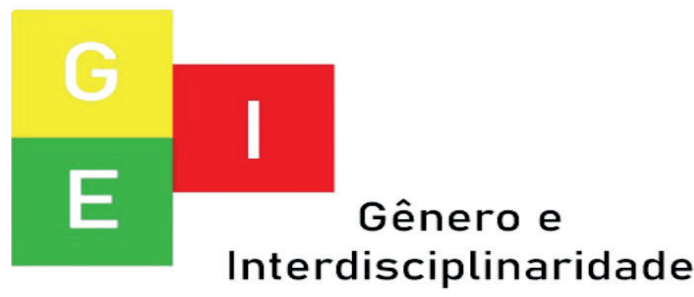


ISSN: 2675-7451

Vol. 02 - n 06 - ano 2021

Editora Acadêmica Periodicojs

Table (4) Results of the correlation test between the use of different types of radio programs with research interface variables

\begin{tabular}{|c|c|c|c|c|}
\hline Interface variables & \multicolumn{4}{|c|}{ Application rate } \\
\hline Evaluation of officials & $\begin{array}{l}\text { Kendall's tau-b }=0 / 040 \\
\text { Gamma }=0 / 068 \\
\mathrm{Sig}=0 / 186\end{array}$ & $\begin{array}{l}\text { Kendall's tau-b }=-0 / 063 \\
\text { Gamma }=0 / 124 \\
\text { Sig }=0 / 000\end{array}$ & $\begin{array}{l}\text { Kendall's tau-b }=0 / 098 \\
\text { Gamma }=0 / 183 \\
\text { Sig }=0 / 052\end{array}$ & $\begin{array}{l}\text { Kendall's tau-b }=-0 / 009 \\
\text { Gamma }=-0 / 019 \\
\text { Sig }=0 / 845\end{array}$ \\
\hline Universalism & $\begin{array}{l}\text { Kendall's tau-b }=0 / 117 \\
\text { Gamma }=0 / 198 \\
\text { Sig }=0 / 008\end{array}$ & $\begin{array}{l}\text { Kendall's tau-b }=-0 / 091 \\
\text { Gamma }=0 / 175 \\
\text { Sig }=0 / 044\end{array}$ & $\begin{array}{l}\text { Kendall's tau-b }=0 / 111 \\
\text { Gamma }=0 / 205 \\
\text { Sig }=0 / 017\end{array}$ & $\begin{array}{l}\text { Kendall's tau-b }=0 / 027 \\
\text { Gamma }=0 / 054 \\
\text { Sig }=0 / 539\end{array}$ \\
\hline Social commitment & $\begin{array}{l}\text { Kendall's tau-b }=0 / 010 \\
\text { Gamma }=0 / 017 \\
\text { Sig }=0 / 839\end{array}$ & $\begin{array}{l}\text { Kendall's tau-b }=0 / 153 \\
\text { Gamma }=0 / 311 \\
\text { Sig }=0 / 001\end{array}$ & $\begin{array}{c}\text { Kendall's tau-b }=-0 / 055 \\
\text { Gamma }=-0 / 106 \\
\text { Sig }=0 / 246\end{array}$ & $\begin{array}{c}\text { Kendall's tau-b }=0 / 092 \\
\text { Gamma }=0 / 193 \\
\text { Sig }=0 / 062\end{array}$ \\
\hline Feeling of security & $\begin{array}{l}\text { Kendall's tau-b }=-0 / 181 \\
\text { Gamma }=-0 / 294 \\
\text { Sig }=0 / 000\end{array}$ & $\begin{array}{l}\text { Kendall's tau-b }=-0 / 136 \\
\text { Gamma }=-0 / 252 \\
\mathrm{Sig}=0 / 007\end{array}$ & $\begin{array}{l}\text { Kendall's tau- } b=-0 / 248 \\
\text { Gamma }=-0 / 438 \\
\text { Sig }=0 / 000\end{array}$ & $\begin{array}{c}\text { Kendall's tau-b }=-0 / 174 \\
\text { Gamma }=-0 / 338 \\
\text { Sig }=0 / 000\end{array}$ \\
\hline $\begin{array}{l}\text { Environmental } \\
\text { assessment }\end{array}$ & $\begin{array}{l}\text { Kendall's tau-b }=-0 / 026 \\
\text { Gamma }=0 / 045 \\
\text { Sig }=0 / 560\end{array}$ & $\begin{array}{l}\text { Kendall's tau-b }=0 / 106 \\
\text { Gamma }=0 / 201 \\
\text { Sig }=0 / 029\end{array}$ & $\begin{array}{l}\text { Kendall's tau-b }=0 / 048 \\
\text { Gamma }=0 / 090 \\
\text { Sig }=0 / 292\end{array}$ & $\begin{array}{l}\text { Kendall's tau-b }=-0 / 035 \\
\text { Gamma }=-0 / 068 \\
\mathrm{Sig}=0 / 493\end{array}$ \\
\hline
\end{tabular}

As can be seen, there is a significant relationship between the level of radio use and the variables of generalization interface and sense of security. Significant levels $(\mathrm{sig}=0.008)$ of generalism and (sig $=0.000)$ sense of security as well as gamma and tau-b coefficients of Kendall (Kendall's tau-b $=0.117,0.19($ Gamma $=$ sign for universalism). Gives a significant relationship in a positive direction and Kendall's tau-b gamma and tau coefficients
$(-0.181=$ Kendall's tau-b, 0.294

$($ Gamma $=-$ for the variable of social security) a significant relationship and correlation is established in a negative direction This means that the higher the use of radio, the higher the level of universalism, and that the higher the use of radio, the lower the sense of social security.

There is a significant relationship between the use of radio news programs and all variables of research interfaces.

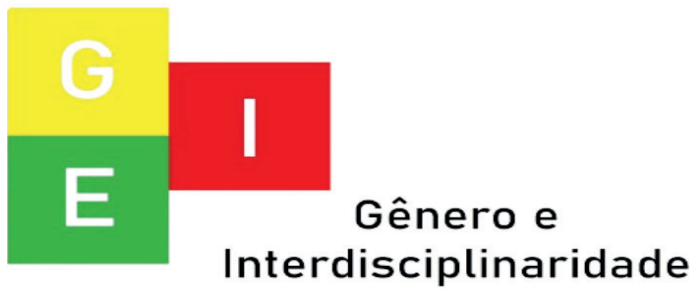


ISSN: 2675-7451

Vol. 02 - n 06 - ano 2021

Editora Acadêmica Periodicojs

Significant levels $(\operatorname{sig}=0.000)$ have a negative correlation and Evaluation of officials, $(\mathrm{sig}=$ other variables have a positive 04.04) universalism, $(\mathrm{sig}=0.001) \quad$ correlation with the mentioned social commitment, $(\mathrm{sig}=0.007) \quad$ variable.

sense of security, $(\operatorname{sig}=0.029)$ The use of radio enEnvironmental assessment as tertainment programs signifiwell as Kendall's tau-b gamma cantly influences the variables and tau-b coefficients (Kendall's of generalism and the feeling of tau-b $=0.063$, Gamma $=$ for security. Significant levels (sig evaluation by officials, Kendall's $\quad=0.017$ ) of generalism and (sig tau-b $=0.091$, Gamma $=$ for ge$=0.000)$ of sense of security as neral Orientalism, Kendall's tau$-\mathrm{b}=0.153(\mathrm{Gamma}=$ for social well as gamma and tau-b coefficients of Kendall (Kendall's taucommitment, Kendall's tau-b = $-\mathrm{b}=0.111,0.205($ Gamma $=$ sign $0.136=0.252(\mathrm{Gamma}=-$ for $\mathrm{a}$ for universalism). The donor is sense of security and Kendall's $=0.106)$ tau-b, 201/0 (Gamma $=$ a significant relationship in a positive direction and Kendall's tau-b gamma and tau coefficients $(-0.234=$ Kendall's tau-b, 0.438 $($ Gamma $=-$ for the social security sense variable and a significant correlation in a negative direction is established). This means that the more you use radio entertainment programs, the more general it becomes, and the more you use

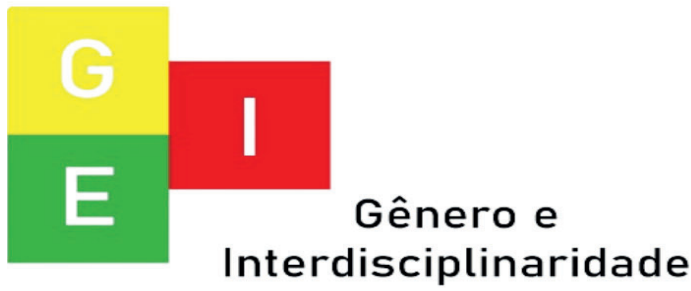


Vol. 02 - n 06 - ano 2021

Editora Acadêmica Periodicojs

radio entertainment programs, the lower your sense of social security.

Among the research interface variables, the use of radio training programs only significantly affects the social security feeling variable (sig $=0.000$ ). Kendall's tau-b gamma and tau coefficients $(-0.174=0.338$ $($ Gamma $=-$ indicates a negative correlation between the mentioned variables, which means that the more the use of radio training programs, the lower the sense of social security. Between the use of radio training programs and evaluation variables from officials , Universalism, social commitment and evaluation of the environment are not considered a significant relationship.

The results show that the use of radio as well as radio programs affects the variables of evaluation of officials, generali- zation, social commitment, sense of security and evaluation of the environment. The results of sub-analyzes between different variables of radio media confirm these relationships. he does. In the following, the relationship between research interface variables and types of social trust will be tested. Table (5) shows the relationship between the research mediating variables, ie the variables of evaluation of officials, generalization, social commitment, sense of security and evaluation of the environment with different types of social trust.

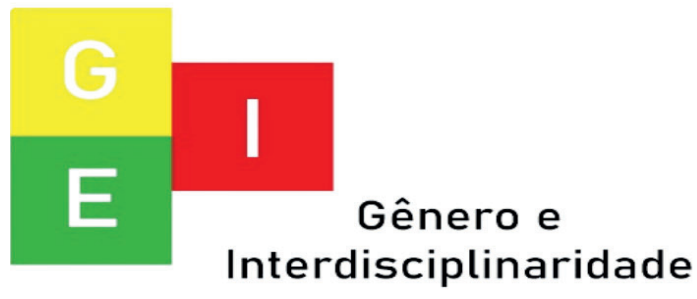


ISSN: $2675-7451$

Vol. 02 - n 06 - ano 2021

Editora Acadêmica Periodicojs

Table (5) Results of the correlation test between research interface variables with different types of social trust

\begin{tabular}{|c|c|c|c|c|c|}
\hline \multirow[b]{2}{*}{$\begin{array}{l}\text { dependent } \\
\text { variables }\end{array}$} & \multicolumn{5}{|c|}{ Interface variables } \\
\hline & Evaluation of officials & Universalism & $\begin{array}{l}\text { Social } \\
\text { Commitment }\end{array}$ & Feeling of security & $\begin{array}{l}\text { Environmental } \\
\text { assessment }\end{array}$ \\
\hline \multirow[t]{3}{*}{ Interpersonal trust } & $\mathrm{K}$ tau-b $=-0 / 114$ & $\mathrm{~K}$ tau-b $=0 / 165$ & $\mathrm{~K}$ tau-b $=0 / 018$ & $\mathrm{~K}$ tau-b $=-0 / 008$ & $\mathrm{~K}$ tau-b $=0 / 160$ \\
\hline & Gamma $=-0 / 026$ & Gamma $=0 / 295$ & Gamma $=-0 / 034$ & Gamma $=-0 / 015$ & Gamma $=0 / 292$ \\
\hline & $\operatorname{Sig}=0 / 769$ & Sig $=0 / 000$ & $\mathrm{Sig}=0 / 709$ & $\operatorname{Sig}=0 / 857$ & $\operatorname{Sig}=0 / 000$ \\
\hline \multirow[t]{3}{*}{ General trust } & $\mathrm{K}$ tau-b $=0 / 038$ & $\mathrm{~K}$ tau-b $=0 / 203$ & $\mathrm{~K}$ tau-b $=0 / 089$ & $\mathrm{~K}$ tau-b $=-0 / 078$ & $\mathrm{~K}$ tau-b $=-0 / 034$ \\
\hline & Gamma $=0 / 067$ & Gamma $=0 / 336$ & Gamma $=0 / 1159$ & Gamma $=-0 / 130$ & Gamma $=-0 / 058$ \\
\hline & $\operatorname{Sig}=0 / 405$ & Sig $=0 / 000$ & $\operatorname{Sig}=0 / 075$ & $\mathrm{Sig}=0 / 099$ & $\operatorname{Sig}=0 / 484$ \\
\hline \multirow[t]{3}{*}{ Institutional trust } & $\mathrm{K}$ tau-b $=0 / 252$ & $\mathrm{~K}$ tau-b $=0 / 119$ & $\mathrm{~K}$ tau-b $=0 / 220$ & $\mathrm{~K}$ tau-b $=0 / 232$ & $\mathrm{~K}$ tau-b $=0 / 244$ \\
\hline & $\mathrm{Gamma}=0 / 423$ & Gamma $=0 / 196$ & Gamma $=0 / 382$ & Gamma $=0 / 377$ & Gamma $=0 / 407$ \\
\hline & $\mathrm{Sig}=0 / 000$ & $\mathrm{Sig}=0 / 016$ & $\operatorname{Sig}=0 / 082$ & Sig $=0 / 000$ & Sig $=0 / 000$ \\
\hline
\end{tabular}

Among the types of social trust, the variable of evaluation of officials has a significant relationship with institutional trust $(\mathrm{sig}=0.000)$. Kendall's tau-b gamma and tau coefficients $(0.252=$ Kendall's tau-b, 0.423$)$ Gamma shows that there is a significant correlation between these two variables in a positive direction, which means that the higher the positive evaluation of the officials. The level of institutional trust also increases. There is no significant relationship between the level of positive evaluation of officials and interpersonal trust and general trust.

There is a significant relationship between the degree of generalism of the respondents and all three types of social trust. Significant levels $(\operatorname{sig}=0.000)$ Interpersonal trust, $(\mathrm{sig}=0.000)$ General trust, $(\mathrm{sig}=0.016)$ Institutional trust as well as Kendall's tau-b gamma and tau coefficients $(0.165)$, Gamma $=$ for interpersonal trust, Kendall's tau-b = 0.203, Gamma $=$ for public trust,

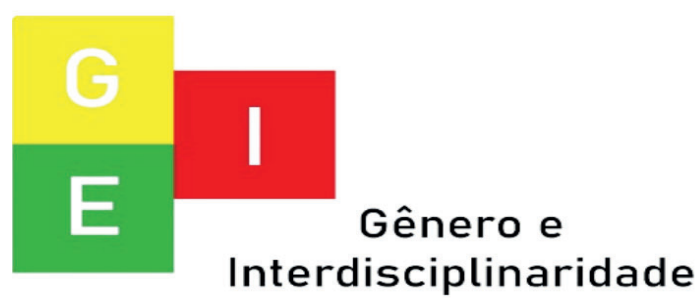


Vol. 02 - n 06 - ano 2021

Editora Acadêmica Periodicojs

Kendall's tau-b, 0.199 (Gamma = for trust Institution shows a significant relationship between the mentioned variables. The correlation value in all three types of relationships is in a positive direction. Therefore, the higher the degree of generalization, the higher the level of social trust in all three types.

Among the types of social trust, only institutional trust has a significant relationship with the level of social commitment of the respondents $(\operatorname{sig}=0.000)$. Kendall's tau-b coefficients (Kendall's tau-b $=0.225$, Gamma) show that the correlation of variables is positive and significant. This means that the higher the level of social commitment of the respondents, the higher their institutional trust. There is no significant relationship between individuals' social commitment and interpersonal trust and general trust. Although there is a significant correlation between them, this correlation is not significant. There is a significant relationship between the level of social security and institutional trust $(\mathrm{sig}=0.000)$. Kendall's tau-b coefficients (Kendall's tau$-\mathrm{b}=0.232$, Gamma 0.377) show that the correlation of variables is positive and significant. This means that the higher the level of social security of the respondents, the higher their institutional trust. There is no significant relationship between individuals' social commitment and interpersonal trust and general trust. Although there is a significant correlation between them, this correlation is not significant.

The degree of evaluation of the environment significantly affects interpersonal social trust and institutional trust. Significant levels (sig $=0.000)$ of in-

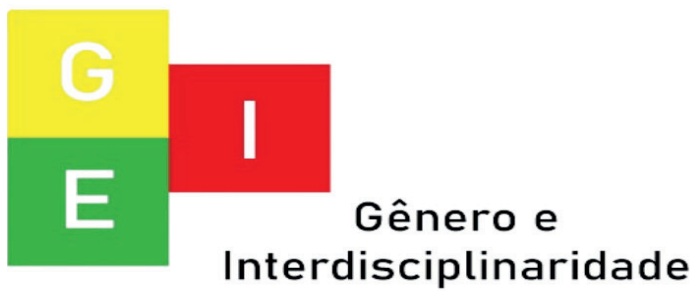


ISSN: 2675-7451

Vol. 02 - n 06 - ano 2021

Editora Acadêmica Periodicojs

terpersonal trust, $(\mathrm{sig}=0.000)$ of institutional trust as well as Kendall's tau-b gamma and tau coefficients $(0.160=$ Kendall's tau-b, $0.292(\mathrm{Gamma}=$ for intermediate trust) Individual, (Kendall's tau$-\mathrm{b}=0.244,0.407(\mathrm{Gamma}=$ for institutional trust) indicates a significant relationship between the mentioned variables. Correlation coefficients indicate a positive direction between the mentioned variables, which means that whatever the evaluation The positive goes beyond the environment, the level of interpersonal trust and institutional trust also goes up.

The study shows that there is a significant relationship between research mediating variables and the level of social trust in its types of trust. All research variables have a significant relationship with institutional trust, but in the other two types of social trust, interpersonal trust and general trust, relationships are significant in some but not significant. In general, it can be said that there is a significant relationship between variables. Research mediators and the level of social trust are observed.

\section{Conclusion}

There is a significant relationship between radio usage and general trust. There is a relatively good relationship between these two variables in a positive direction, which means that the higher the use of radio, the higher the level of public trust. There is no significant relationship between the use of radio and institutional trust. There is no significant relationship between radio usage and institutional trust. Examining the relationship between the use of radio programs with diffe-

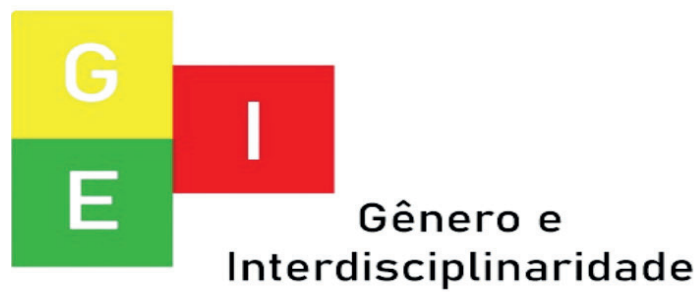


Vol. 02 - n 06 - ano 2021

Editora Acadêmica Periodicojs

rent types of social trust shows that the use of radio news programs affects interpersonal trust, so there is a significant relationship between the use of radio news programs and interpersonal trust. There is a significant difference between the use of radio news programs and interpersonal trust. Also, the use of radio has a significant effect on public trust and that the impact of radio news programs on general social trust is greater than interpersonal social trust. But there is no significant relationship between the use of radio news programs and institutional trust. The use of entertainment programs among the types of social trust only significantly affects general trust. But there is no significant relationship between the use of radio entertainment programs and interpersonal trust and institutional trust.
There is a significant relationship between the use of radio training programs and interpersonal trust. The results show that the correlation direction is negative, which means that the lower the use of radio training programs, the higher the interpersonal trust. There is a significant relationship between the use of radio training programs and the level of general trust. There was no significant relationship between the use of educational programs and institutional trust.

Examining the relationship between the use of different types of radio programs with the intermediate variables of the research shows that there is a significant relationship between the use of radio and the intermediate variables of generalism and the feeling of security. Levels of meaning for generalism indicate a significant relationship

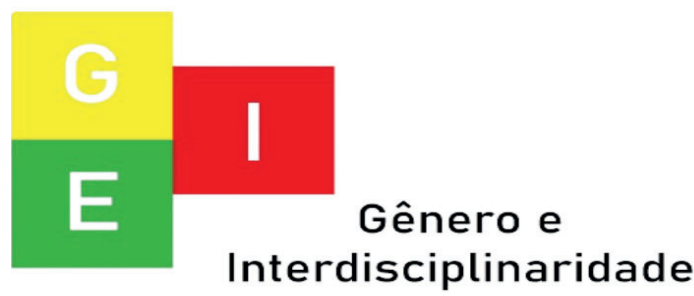


ISSN: 2675-7451

Vol. 02 - n 06 - ano 2021

Editora Acadêmica Periodicojs

in a positive direction and for the variable of feeling of social security, a significant relationship and correlation is established in a negative direction. This means that the higher the use of radio, the higher the level of universalism, and that the higher the use of radio, the lower the sense of social security. There is a significant relationship between the use of radio news programs and all variables of research interfaces. Among the interface variables, only the variable of feeling of social security has a negative correlation with the rate of use of radio news programs, and the rest of the variables have a positive correlation with the mentioned variable. The use of radio entertainment programs significantly influences the variables of generalism and the feeling of security. The higher the use of radio entertainment programs, the higher the level of generalization, and the higher the use of radio entertainment programs, the lower the sense of social security.

Among the research interface variables, the use of radio training programs only significantly affects the feeling of social security, indicating a negative correlation between these variables, which means that the more the use of radio training programs, the feeling of social security. It comes lower. There is no significant relationship between the use of radio training programs and the evaluation variables of officials, generalization, social commitment and evaluation of the environment. The results show that the use of radio as well as radio programs affects the variables of evaluation of officials, generalization, social commitment, sense of security and evaluation of the environ-

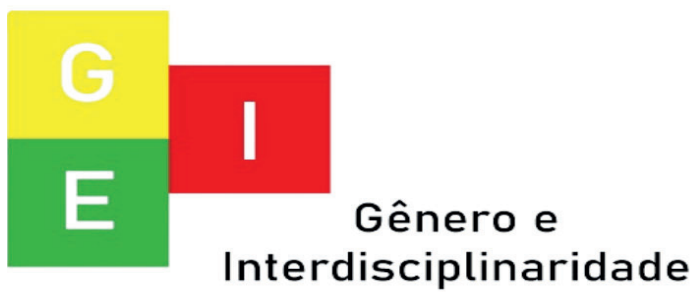


ISSN: 2675-7451

Vol. 02 - n 06 - ano 2021

Editora Acadêmica Periodicojs

ment. The results of sub-analyzes between different variables of radio media confirm these relationships. he does. Among the types of social trust, the variable of evaluation of officials has a significant relationship with institutional trust. There is a significant correlation between these two variables in a positive direction, which means that the higher the positive evaluation of officials, the higher the level of institutional trust. There is no significant relationship between positive evaluation of officials and interpersonal trust and general trust. Along with the effect of intermediate variables on the social trust variable, the results showed that there is a significant relationship between the degree of generalization of respondents and all three types of social trust. Among the types of social trust, only institutional trust has a sig- nificant relationship with the level of social commitment of respondents, which is a positive and significant correlation of variables. There is a significant relationship between the sense of social security and institutional trust. There is no significant relationship between individuals' social commitment and interpersonal trust and general trust. Although there is a significant correlation between them, this correlation is not significant.

The degree of evaluation of the environment significantly affects interpersonal social trust and institutional trust. The study shows that there is a significant relationship between research mediating variables and the level of social trust in its types of trust. All research variables have a significant relationship with institutional trust, but in the other two types of social trust, interperso-

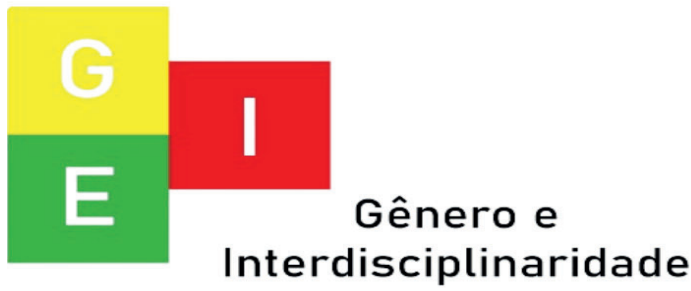


ISSN: 2675-7451

Vol. 02 - n 06 - ano 2021

Editora Acadêmica Periodicojs

nal trust and general trust, relationships are significant in some but not significant. In general, it can be said that there is a significant relationship between variables. Research mediators and the level of social trust are observed. Finally, it can be stated that the use of radio has a direct effect on social trust and also indirectly affects the level of social trust through research variables.

\section{Refrences}

Dalgren, Peter. Television and the general public, translated by Mehdi Shafaqati, Soroush Publications, Tehran, 2001.

Delhey,jon-Newton Kenneth. (2002)"Who Trusts?The Origins of Social Trust in Seven Nations"Research Unit "Social Structur and Social Reporting" SocialScience Research Cen- ter Berlin(wzb)Reichpietschufer 50.d 10785.

Giddens, Anthony. Reconciliation, translated by Nasser Movafeghian, published, Tehran, 1999

Giddens, Anthony. Sociology, translated by Manouchehr Sabouri, published, Tehran, 2003

Gerald,Coreg.(1996)"Theory and Practices of Counseling and Psychology" Brooks/col Publishing Company an International, London Thomson Publishing Company.

Luhmann,Niklas.(2000)"Familiarity Confidence,Trust Problems and Alternatives:In Meaking and Breaking Cooperative Relations" Electtronic edition,Department of Sociology,University Of Oxford.Chapter 6,pp.94107.

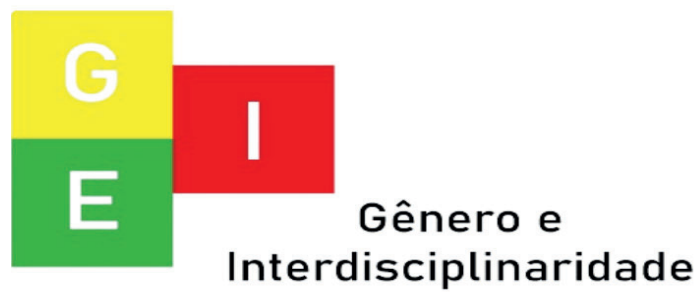


Vol. 02 - n 06 - ano 2021

Editora Acadêmica Periodicojs

Misztal,Barbara.(1996)"Trust in Perse,Elizabeht.m.(2001)"Media

Modern Societies" Cambridge Effects and Socity" Lrence ErlPolity Press. baum Associates.inc.

Moy,Patricia.Pfau,Michael. P u t n a m, D. R o b e r t . (2000)"With Malice Toward (1998)"Bowling Alone:America's All?The Media and Public Confi- Declining Social Capital'Journal dence in Democratic Institution” of Democracy.01/95 vol.6 no,1. Westport,ct,Usa:Green Wood Publishing Groups ,Incorporate- Pearson, Christopher. The mead,pii. ning of modernity, translated by Ali Asghar Saeedi, Kavir PuN,Cappella,Joseph.(2002)"Cy- blications, Tehran, 2001 nicism and Social Trust in the NewMedia Invironment'Journal

Putnam ,D.Robert. of Communication:jan,01,2002

Norris,pippa.(2002)"Social Capital and ICT's:widing and Reinforcing Social Networks?" Presented at "International Forum on Social Capital foc Economic Revival"Held by Economic and Scial Research Institute,Cabinet Office,Japan,Tokyp.
(2000)"Bowling Alone:The

Callapse and Revival of American Community New york:Simon and Schuster:Pp:288-290 Stevenson,nick.(2002)"Undefstanding Media Cultures"Sage Publications,Londons.

Stone,w.(2001)"Measuring Social

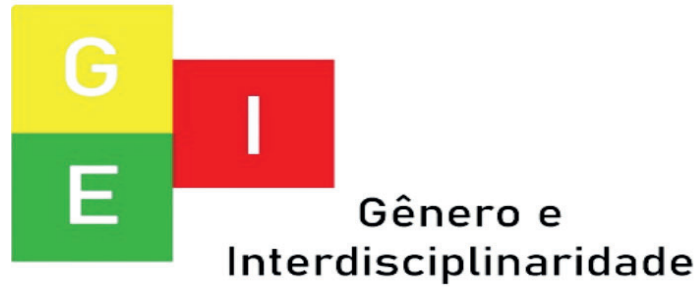


ISSN: 2675-7451

Vol. 02 - n 06 - ano 2021

Editora Acadêmica Periodicojs

Capital:Towards a Theoretically

Informed Measurement Fra-

mework for Researching Social

Capital in Family and Commu-

nity Life"Australian Institute of

Family Studies, Research paper

No,24.

Sztompka,pioter.(1999)"Trust:A

Sociology Theory" Cambridge

University Press.United King-

dom, Cambridge,Trumpington

Street

V.Shah,Dhavan.(1998)"Civic Engagement,Interpersonal Trust and Television Use:An individual - Level Assessment of Social Capital" Political Psychology,vol;19 No,3.

Uslaner,Eric.M.91998)"Social Capital,Television, and the "MeanWorid":Trust,Optimism, and CivicParticipation" Political Psychology.,vol;19 No,3

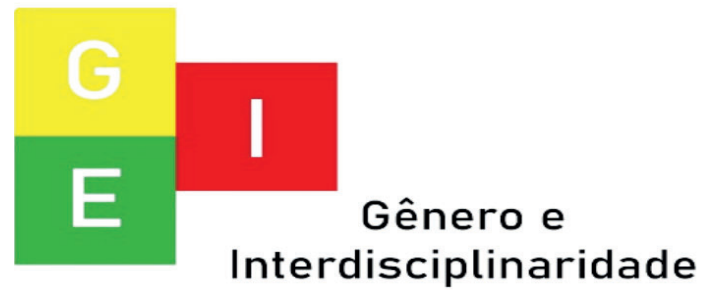

